ISSN 0103-8478

\title{
Metodologias de controle de qualidade de análises granulométricas do solo
}

\author{
Methodologies for quality control of soil particle size analysis \\ Vilson Antonio Klein ${ }^{\mathrm{I}}$ Tiago Madalosso ${ }^{\mathrm{II}}$ José Miguel Reichert $^{\mathrm{III}}$ \\ Luis Eduardo Akiyoshi Sanches Suzuki ${ }^{\mathrm{I}}$ Milton da Veiga ${ }^{\mathrm{v}}$ \\ Jackson Adriano Albuquerque ${ }^{\mathrm{VI}}$ Eloy Antonio Pauletto ${ }^{\mathrm{VII}}$
}

- NOTA -

RESUMO

A qualidade da análise granulométrica é imprescindivel para a adequada classificação textural dos solos e enquadramento no Zoneamento Agroclimático. O objetivo deste trabalho foi avaliar metodologias de controle de qualidade das análises granulométricas. Foram coletadas amostras de solos com diferentes texturas, as quais foram analisadas por cinco laboratórios. $O$ controle da qualidade foi realizado utilizando duas metodologias, uma proposta pelo Instituto Agronômico de Campinas (IAC) e a outra pela Rede Oficial de Laboratórios de Análise de Solo e de Tecido Vegetal dos Estados do RS e SC (ROLAS). Verificou-se maior número de inconformidades para as frações argila e silte, independentemente do método, sendo que o método da ROLAS apresentou maior número de inconformidades (76\% das amostras), principalmente para amostras com teores mais elevados dessas frações. A metodologia da ROLAS com utilização da mediana é mais rigorosa no controle da qualidade das análises.

Palavras-chave: textura do solo, frações granulométricas, métodos de análise.

\section{ABSTRACT}

The quality of particle size analysis is essential for correct soil textural classification and defining the Brazilian Agroclimatic Zoning. The objectives were to evaluate methods of particle size analysis and develop a spreadsheet for use in quality control analyzes. We collected 50 soil samples with different particle size distribution, in RS and SC states of Brazil, which were analyzed by five laboratories in the two states that perform the soil particle size analysis using two methods: one proposed by the Campinas Agronomic Institute (IAC) and the other by the Network of Soil and Plant Tissue Analysis Laboratories of the states of RS and SC (ROLAS). A greater number of disparities were observed for the clay and sand fractions regardless of the method. The ROLAS method had a higher number of mismatches (76\% of samples), especially for samples with higher contents of those two fractions. The use of the median value in the ROLAS methodology is more rigorous in analysis quality control.

Key words: soil texture, particle size fractions, methods of analysis.

A granulometria, que representa as proporções relativas das frações areia, silte e argila do solo, é uma característica que não pode ser alterada pelo seu uso, pois é inerente aos fatores de formação do solo, especialmente o material de origem, e interfere diretamente no grau de compactação (SUZUKI et al., 2008), na disponibilidade de água (REICHERT et al., 2009), na capacidade de troca de cátions (CQFS, 2004) e na classificação do solo (SANTOS et al., 2006), bem como em práticas agrícolas, como na dosagem de nutrientes e corretivos (CQFS, 2004). Grande parte do valor da terra é determinada pela granulometria do solo,

${ }^{\text {I}}$ Faculdade de Agronomia e Medicina Veterinária (FAMV), Universidade de Passo Fundo (UPF), CP 611, 99001-970, Passo Fundo, RS, Brasil. E-mail: vaklein@upf.br. Autor para correspondência.

${ }^{\text {IIC }}$ urso de Graduação em Agronomia, FAMV, UPF, Passo Fundo, RS, Brasil.

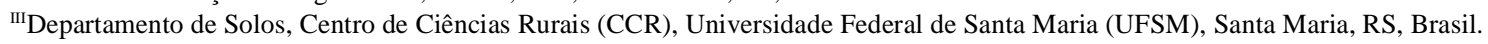

${ }^{\text {IV }}$ Centro de Desenvolvimento Tecnológico (CDTec), Universidade Federal de Pelotas (UFPel), Pelotas, RS, Brasil.

${ }^{\vee}$ Empresa de Pesquisa Agropecuária e Extensão Rural de Santa Catarina (Epagri), Estação Experimental de Campos Novos, Campos Novos, SC, Brasil.

${ }^{\mathrm{VI}}$ Centro de Ciências Agroveterinárias, Universidade do Estado de Santa Catarina (UDESC), Lages, SC, Brasil.

VIIDepartamento de Solos, Faculdade de Agronomia Eliseu Maciel (FAEM), UFPel, Capão do Leão, RS, Brasil. 
sendo que solos com maior teor de argila geralmente são melhores para fins agrícolas, em função das suas propriedades químicas e físicas (REICHARDT, 1987), sendo isso reconhecido a partir da exigência de análise granulométrica para tipificação do solo no Zoneamento Agroclimático (BRASIL, 2008).

Segundo ZULLO (1985), nos laboratórios de análises químicas, normalmente são utilizadas amostras-controle, cujos valores verdadeiros são estimados com certa exatidão e precisão. Para esse controle, são utilizados dois sistemas: o primeiro consiste em repetir, em intervalos regulares de amostras analisadas, a análise de uma única amostracontrole, enquanto o segundo consiste em repetir, em intervalos irregulares, a análise de uma entre várias amostras-controle.

Diante da importância da determinação da granulometria do solo e em função das diferentes formas e metodologias adotadas pelos diversos laboratórios responsáveis por esse tipo de análise, é importante alguma forma de controle desses resultados. Em função disso, foi desenvolvido este trabalho com o objetivo de avaliar duas metodologias de controle de qualidade das análises granulométricas.

Para desenvolvimento deste trabalho, foram coletadas amostras de solo em diferentes locais nos estados do RS e SC, com grande variação nos teores de argila, silte e areia. Os resultados das análises granulométricas foram comparados por duas metodologias, sendo uma proposta pelo Instituto Agronômico de Campinas (IAC) e a outra pela Rede Oficial de Laboratórios de Análise de Solo e de Tecido Vegetal dos Estados do RS e SC (ROLAS).

O método do IAC foi adaptado de QUAGGIO et al. (1994), em que se calculou a média e o desvio padrão da média (S) para cada uma das frações granulométricas (areia, silte e argila) das amostras. As faixas de aceitação dependem do coeficiente de variação do conjunto de resultados de cada fração analisada (Tabela 1). Um segundo intervalo de tolerância baseou-se na magnitude da média (Tabela 1), definido pela Comissão de Física de Solos do Núcleo Regional Sul da Sociedade Brasileira de Ciência do Solo (NRS-SBCS). Os valores situados fora da faixa calculada receberam três asteriscos e foram removidos do conjunto de dados antes da segunda rodada de cálculos. O mesmo procedimento foi repetido com as amostras remanescentes, atribuindo-se dois asteriscos para as que se situaram fora da segunda faixa calculada, removendo-se novamente as amostras excluídas da faixa de aceitação. As médias situadas fora da faixa em uma terceira rodada de análise receberam um asterisco, enquanto as que se situaram dentro da faixa não receberam asteriscos. Desse modo, as amostras receberam nenhum, um, dois ou três asteriscos, dependendo do número de inconformidades atribuídas.

No método da ROLAS, atualmente utilizado para avaliar a qualidade e confiabilidade dos resultados de fertilidade do solo fornecidos pelos laboratórios de rotina de fertilidade do solo nos estados de Santa Catarina e Rio Grande do Sul, calculou-se a mediana e o desvio padrão da mediana para cada uma das frações granulométricas. A vantagem da utilização da mediana, por ser esta uma medida de tendência central, é de minimizar o efeito de análises discrepantes, no controle de qualidade. O primeiro intervalo foi calculado em função da mediana das amostras, adicionando-se ou subtraindo-se um intervalo correspondente à magnitude da mediana (Tabela 1). Todos os valores situados fora desse intervalo foram penalizados com o número de asteriscos segundo sua dispersão em relação ao desvio padrão da mediana, conforme descrito na tabela 1 . O desvio padrão da mediana foi calculado considerando que os dados representavam toda a população de amostras.

Tabela 1 - Faixas de aceitação da média \pm desvio padrão (s), definidas em função do coeficiente de variação (CV) de cada determinação e intervalo de tolerância, atribuído em função da amplitude do valor da média (Método do IAC) ou mediana (Método da ROLAS), e definição do número de asteriscos para cada amostra, considerando o intervalo dos desvios padrão da mediana ( $\left.\mathrm{S}_{\mathrm{m}}\right)$.

\begin{tabular}{|c|c|c|c|}
\hline \multicolumn{2}{|c|}{$\mathrm{CV}(\%)$} & \multicolumn{2}{|c|}{ Faixa de aceitação } \\
\hline \multicolumn{2}{|c|}{$\geq 40$} & \multicolumn{2}{|c|}{ Média $\pm 1,0$ desvio padrão } \\
\hline \multicolumn{2}{|c|}{$\geq 20 \mathrm{e}<40$} & \multicolumn{2}{|c|}{ Média $\pm 1,5$ desvio padrão } \\
\hline \multicolumn{2}{|c|}{$<20$} & \multicolumn{2}{|c|}{ Média $\pm 2,0$ desvio padrão } \\
\hline Média ou mediana & Faixa de tolerância (\%) & Faixa da mediana $\pm S_{\mathrm{m}}$ & Asteriscos \\
\hline$\geq 60$ & $+5,0$ & $\leq \pm 1,0$ & 0 \\
\hline$\geq 40<60$ & $+4,0$ & $>+1,0 \leq \pm 1,5$ & 1 \\
\hline$\geq 20<40$ & $\pm 3,0$ & $> \pm 1,5 \leq \pm 2,0$ & 2 \\
\hline$<20$ & $+2,0$ & $>+2,0$ & 3 \\
\hline
\end{tabular}

Ciência Rural, v.43, n.5, mai, 2013. 
Os resultados evidenciaram menor número de inconformidades (menor número de asteriscos) para a fração areia (Figura 1), o que pode ser atribuído ao fato de essa fração ser inerte, sem cargas e com baixa capacidade de floculação, bem como à possibilidade de sua separação por peneiramento, propiciando uma maior precisão às determinações (KLEIN, 2012). As frações silte e argila obtiveram número semelhante de asteriscos, sendo que cerca de 3/4 do total de asteriscos foi atribuído a essas duas frações. Geralmente, a fração argila é a responsável pelas inconsistências nos resultados pela sua dificuldade de dispersão.
Quanto aos métodos testados (IAC e ROLAS), independente da fração do solo, houve um maior número de inconformidades para o método da ROLAS, sendo que $76 \%$ das amostras apresentaram um maior número de asteriscos do que o método do IAC e, em $15 \%$ das amostras, o número de asteriscos se equiparou nos dois métodos (Figura 1). A média dos teores das frações das amostras em que o número de asteriscos foi maior e menor para o método do IAC em relação ao da ROLAS foi de, respectivamente, 25 e 35\%, demonstrando uma tendência de que teores maiores seriam mais penalizados pelo método da ROLAS e valores menores seriam mais penalizados

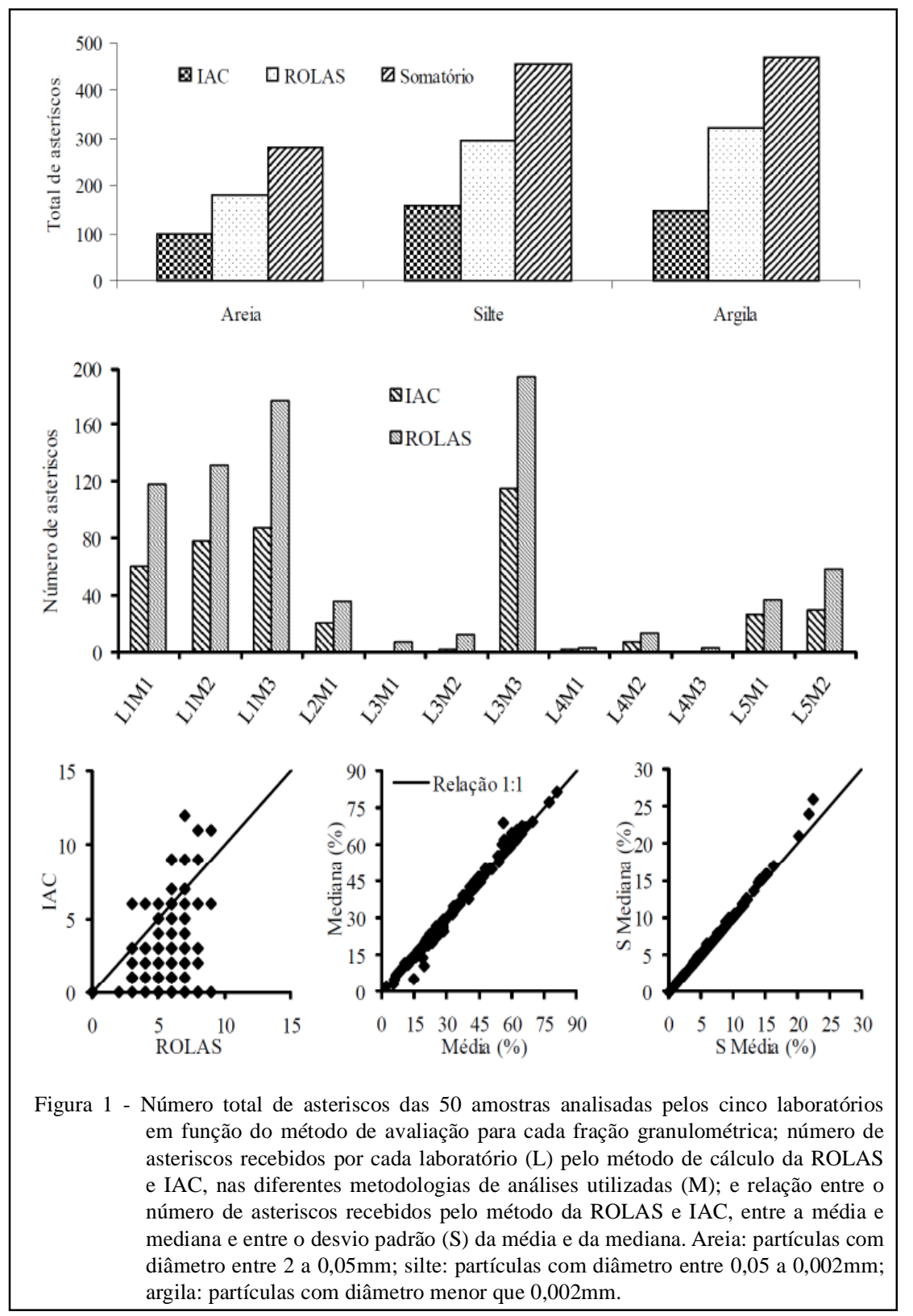

Ciência Rural, v.43, n.5, mai, 2013. 
pelo método do IAC. A média dos teores nas amostras em que o número de asteriscos se igualou nos dois métodos foi de $28 \%$.

O método da ROLAS atribuiu aos laboratórios, em média, 1,8 vezes o número de asteriscos do que o método do IAC. Para o laboratório 4, na metodologia 3 (L4M3), houve apenas três inconformidades para o método ROLAS e nenhuma para o método do IAC, sendo este o laboratório que obteve, em geral, o menor número de asteriscos (Figura 1). Para um mesmo laboratório (L3), a metodologia de determinação da granulometria teve grande influência no número de inconformidades, variando de uma a 115 para o método IAC e de 7 a 194 para o método da ROLAS. Assim, para este laboratório, os problemas podem estar associados à metodologia, à calibração dos equipamentos e ou erro humano.

A relação entre a média e a mediana das frações granulométricas foi próxima de 1:1 para a maioria das amostras, sendo que, em 14 das 150 amostras (50 solos x 3 frações), os valores da média foram iguais aos da mediana. Na população avaliada, nos valores menores, há tendência da média ser maior do que a mediana, sendo o inverso observado nos valores de maior magnitude (Figura 1). Quanto ao desvio padrão da média em relação ao da mediana, também houve uma forte relação 1:1 para valores de desvio padrão inferiores a $15 \%$. Acima desse valor, observou-se uma tendência dos desvios padrão da mediana serem maiores do que os da média.

Fica demonstrado, portanto, a potencialidade de uso de um sistema de controle de qualidade para a análise granulométrica do solo.Ambas as metodologias de controle de qualidade mostraramse eficientes em diagnosticar as inconformidades nos resultados das análises. No entanto, o método de controle de qualidade para análise granulométrica é mais rigoroso pela metodologia da ROLAS do que do IAC. As frações granulométricas com maior percentual de inconformidades são o silte e a argila.

\section{REFERÊNCIAS}

BRASIL. Ministério da Agricultura, Pecuária e Abastecimento. Secretaria de Política Agrícola. Instrução Normativa n.2, de 9 de outubro de 2008. Diário Oficial da União, n.193, Seção 1, p.5, de 13 de outubro de 2008 .

COMISSÃO DE QUÍMICA E FERTILIDADE DO SOLO-RS/ SC. Manual de adubação e calagem para os estados do Rio Grande do Sul e Santa Catarina. 10.ed. Porto Alegre: SBCS/ CQFS, 2004. 400p.

KLEIN, V.A. Física do solo. 2.ed. Passo Fundo: EDIUPF, 2012. 240p.

QUAGGIO, J.A. et al. Evolution of the analytical quality of soil testing laboratories integrated in a sample exchange program. Communications of Soil Science and Plant Analysis, v.25, n.7\&8, p.1007-1014, 1994.

REICHARDT, K. A água em sistemas agrícolas. São Paulo: Manole. 1987. 188p.

REICHERT, J.M. et al. Estimation of water retention and availability in soils of Rio Grande do Sul. Revista Brasileira de Ciência do Solo, v.33, p.1547-1560, 2009. Disponível em: <http:// dx.doi.org/10.1590/S0100-06832009000600004>. Acesso em: 12 abr. 2012. doi: 10.1590/S0100-06832009000600004.

SANTOS, H.G. et al. Sistema brasileiro de classificação de solos. 2.ed. Rio de Janeiro-RJ: Embrapa Solos, 2006. 306p.

SUZUKI, L.E.A.S. et al. Estimativa da suscetibilidade à compactação e do suporte de carga do solo com base em propriedades físicas de solos do Rio Grande do Sul. Revista Brasileira de Ciência do Solo, v.32, n.3, p.963-973, 2008. Disponível em: <http://dx.doi.org/10.1590/S0100-06832008000300006>. Acesso em: 12 abr. 2012. doi: 10.1590/S0100-06832008000300006.

ZULLO, M.A.T. Método para controle de qualidade de laboratórios analíticos de rotina. Bragantia, v.44, p.209-215, 1985. Disponível em: <http://dx.doi.org/10.1590/S0006-87051985000100018>. Acesso em: 12 abr. 2012. doi: 10.1590/S0006-87051985000100018. 